\title{
Health and Wellness Centre for Better Health Care Delivery System in India: A Mirage or a New Hope Glass
}

\author{
Deepak Saxena $^{1 *}$ and Sandul Yasobant ${ }^{2}$ \\ ${ }^{1}$ Indian Institute of Public Health Gandhinagar, Gujarat, India \\ ${ }^{2}$ Center for Development Research (ZEF), Bonn, Germany \\ *DS and SY contributed equally to this work
}

*Corresponding author: Dr. Deepak Saxena, Indian Institute of Public Health, Gandhinagar, Opp. Air Force Head Quarters, Nr

Lekawada Bus Stop, Gandhinagar 382042, Gujarat, India

ARTICLE INFO

Received: 幽 December 22, 2019

Published: 幽 January 29, 2020

Citation: Deepak Saxena, Sandul Yasobant. Health and Wellness Centre for Better Health Care Delivery System in India: A Mirage or a New Hope Glass. Biomed J Sci \& Tech Res 25(1)-2020. BJSTR. MS.ID.004147.

Keywords: Ayushman Bharat; Health and Wellness Centers; Community Health Officer

\begin{abstract}
With the implementation of the world's largest national health protection scheme in India, it is envisaging health system reformation in the near future. The debate on the introduction of a comprehensive primary health care provider at the grassroots level is yet debatable under this initiative. Most of the professional bodies are arguing to each other on who can be the best primary care provider under this flagship. Keeping this in viewpoint, this letter to the editor provides a snapshot of the situation with the future way forward as a potential solution.
\end{abstract}

Abbreviations: CHO: Community Health Officer; FMGE: Foreign Medical Graduate Examination; HWC: Health and Wellness Centers; IMA: Indian Medical Association; MLHP: Mid-level Health Care Provider; NBE: National Board of Examination

\section{Editorial}

\section{Ayushman Bharat: The largest National Protection Scheme}

India is the hub of national health schemes and is now first country by implementing the world's largest national health protection scheme i.e. Ayushman Bharat Yojana (Pradhan Mantri Jan Arogya Yojana, ModiCare) in 2018 under Ayushman Bharat Mission of Ministry of Health and Family Welfare, India [1]. The scheme aims at making interventions in primary, secondary and tertiary care systems, covering both preventive and promotive health, to address healthcare holistically [2]. One of the key initiatives under the scheme is to provide comprehensive primary health care at the grassroots level through the Health and Wellness centers (HWC) [3]. The HWCs are to provide preventive, promotive, rehabilitative and curative care for an expanded range of services encompassing reproductive and child health services, communicable diseases, non-communicable diseases, palliative care and elderly care, oral health, Ear Nose Throat care, and basic emergency care. The services in HWCs need to be provided through a Mid-level Health Care Provider (MLHP)/Community Health Officer (CHO) placed at an HWC and Medical Officer at primary health centers [4].

\section{Community Health Officer: A Comprehensive Primary Care provider}

Having the human resource constraint in the Indian health system [5] and aiming to provide a better service through the HWCs, Govt. of India introduced 'Certificate in Community Health' for the nurses to become a qualified MHLP/CHO ridiculed as infamous Bridge course [6]. Looking into this challenging task, professionals like Ayush [7] and Dentists [8] also demanded the similar bridge 
course to have an uplift as MHLP. These initiates are most of time criticized by Indian Medical Association-IMA (medical professional body in India) for this type of short courses [9].

\section{Who Can Be A Better CHO?}

As MLHP will be one of the key health personnel in Indian health system, herewith we propose two models for generating the most acceptable CHO/MLHP in India. Looking at the statistics, approximately 63,250 doctors graduate every year within India, whereas only $1 / 3$ rd avails the post-graduation studies. This suggests a huge potential that the fresh trained graduates could be recruited as MHLP in these HWCs as a mandatory service for initial part of their career. While reluctance of fresh graduates even to join primary health center is not new, contemplating them to join HWC seems to be a distant vision. A possible and promising solution to have a regular human resource can be, Indian borne students of Medicine that graduate from the foreign universities. There are approximately 12,000 Medical graduate students who gets trained in various Medical Schools across globe return back to India and apply for the certification exam that allows clinical practice in India i.e. Foreign Medical Graduate Examination (FMGE) conducted by the National Board of Examination (NBE) in India. However, various formal and informal sources suggest FMEG as one of the toughest exams with a success rate of only about only $15 \%$ [10].

\section{Way Forward}

There is a huge potential to tap these FMGE graduates to the Indian health system as a future MLHP/CHOs. There is an urgent need for a larger discussion at policy level at NBE to decide the eligibility qualification of foreign graduates to be posted as MLHP. There needs to be institutionalization of such graduates into MLHP and government can seriously debate on exploring possibilities to induct them at HWC and MLHP. The future public health system should be stringent enough to ensure that healthcare services are not provided randomly. There must be a systematic way forward on how the government envisages and prepare existing system to be resilient enough and making the dream of universal health coverage to be true in the case of India.

\section{Ethics Approval and Consent to Participate}

The present piece of work does not involve human research subjects or use confidential data.

\section{Competing Interests}

The authors declare that they have no competing interests.

\section{References}

1. (2018) Ministry of Health and Family Welfare. Ayushmaan Bharat: National Health Protection Scheme. In: National Health Authority.

2. (2018) Ministry of Finance. Ayushman Bharat for a new India -2022. In: Press Information Bureau, Government of India.

3. (2019) Ministry of Health and Family Welfare. Health and Wellness Centers under Ayushman Bharat. In: Press Information Bureau, Government of India.

4. (2019) National Health Systems Resource Centre. Ayushman Bharat: Comprehensive Primary Health Care through Health and Wellness Centers- Operational Guidelines.

5. Rao M, Rao KD, Kumar AS, Chatterjee M, Sundararaman T, et al. (2011) Human resources for health in India. The Lancet 377: 587-598.

6. (2018) The Pioneer. Govt nurses to undergo bridge course.

7. (2018) Press Information Bureau. Bridge Course for Ayush Doctors. In: Government of India.

8. (2019) Times of India. A bridge course to allow dentists practice as doctors.

9. Sharma NC (2019) IMA opposes gov's proposal to allow dentists practice modern medicine.

10. (2017) Foreign Medical Graduates Examination. Annual Report of the National Board of Examinations.

\section{ISSN: 2574-1241}

DOI: $10.26717 /$ BJSTR.2020.25.004147

Deepak Saxena. Biomed J Sci \& Tech Res

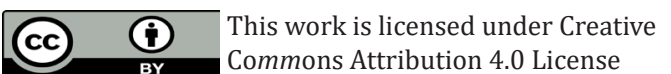

Submission Link: https://biomedres.us/submit-manuscript.php

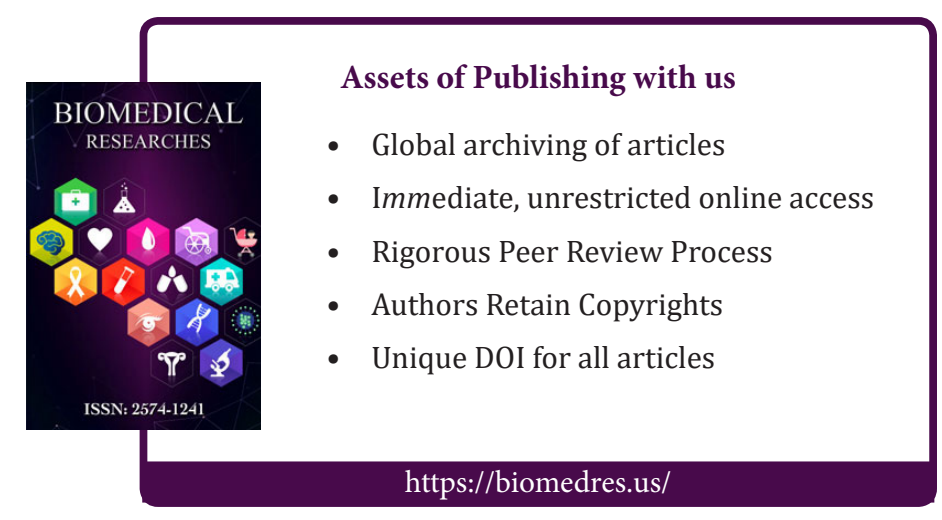

